\title{
Efficient Wide Range Converters (EWiRaC): A new family of high efficient AC-DC Converters
}

Petersen, Lars; Andersen, Michael Andreas E.

Published in:

Twenty-First Annual IEEE Applied Power Electronics Conference and Exposition, 2006. APEC '06.

Link to article, DOI:

10.1109/APEC.2006.1620547

Publication date:

2006

Document Version

Publisher's PDF, also known as Version of record

Link back to DTU Orbit

Citation (APA):

Petersen, L., \& Andersen, M. A. E. (2006). Efficient Wide Range Converters (EWiRaC): A new family of high efficient AC-DC Converters. In Twenty-First Annual IEEE Applied Power Electronics Conference and Exposition, 2006. APEC '06. IEEE. https://doi.org/10.1109/APEC.2006.1620547

\section{General rights}

Copyright and moral rights for the publications made accessible in the public portal are retained by the authors and/or other copyright owners and it is a condition of accessing publications that users recognise and abide by the legal requirements associated with these rights.

- Users may download and print one copy of any publication from the public portal for the purpose of private study or research.

- You may not further distribute the material or use it for any profit-making activity or commercial gain

- You may freely distribute the URL identifying the publication in the public portal 


\section{Efficient Wide Range Converters (EWiRaC): A new family of high efficient AC-DC Converters}

\author{
Lars Petersen \\ ICEpower \\ Gl. Lundtoftevej 1B \\ DK-2800 Kgs. Lyngby, Denmark \\ Email: lpe@bang-olufsen.dk
}

\author{
Michael A.E. Andersen \\ Oersted·DTU, Automation \\ Technical University of Denmark \\ Elektrovej, building 325 \\ DK-2800 Kgs. Lyngby, Denmark \\ Email: ma@oersted.dtu.dk
}

\begin{abstract}
The performance in terms of efficiency of the existing power supplies used for $\mathrm{PFC}$ is very dependent on the input voltage range. The Boost converter is the most commonly used PFC converter because of its simplicity and high efficiency. But, the Boost converter as well as other known converters suffers a major penalty in efficiency when used at the low end of the voltage range $(90 \mathrm{VAC})$ in a universal voltage range application (90-270VAC).

This paper addresses this problem by suggesting a new family of converters that effectively reduces the apparent voltage range with a factor of 2 by changing the converter topology according to the input voltage. This new converter type has been named: Efficient Wide Range Converter (EWiRaC).

The performance of the EWiRaC is experimental verified in a universal input range (90-270VAC) application with an output voltage of $185 \mathrm{VDC}$ capable of $500 \mathrm{~W}$ output power.

The EWiRaC exhibits a 1-2 percentage points higher efficiency compared to a Boost converter using the same power components. This translates into a reduction of the power losses of $15 \%-30 \%$.
\end{abstract}

\section{INTRODUCTION}

The Boost converter is the predominant PFC converter but also SEPIC and dual-switch buck-boost type converters ([1], [2], [3]) are used as alternative topologies. In terms of efficiency the Boost converter is still regarded as the most efficient PFC converter but the alternative topologies provides the ability to convert to an output voltage less than the maximum input voltage. Also inrush current limiting is handled more graceful compared to the Boost converter. Sepic converters are essentially a buck-boost type converter but has like the boost converter an inductor in series with the input at all time which enables smaller size EMI-filters. The Dual-switch Buck-boost converter-arrangement switches between a Boost converter and a Buck converter according to the actual value of the line voltage. The major drawback of this approach is that all the power has to flow through the buck-switch at all time and that the input current is highly discontinuously when the converter is in the buck-mode (large EMI-filter). The EWiRaC family proposed in this paper combines the strong features of both the Boost converter (High efficiency, continues input current) and the
Dual-switch Buck-Boost converter (Selectable output voltage, inherent inrush current limiting, reduced stepup/step-down conversion ratio).

\section{EFFICIENT WIDE RANGe CONVERTERS}

This work on efficient rectifiers has resulted in a new approach to construct high efficient converters that target the universal line range [4]. These ideas are originated in the approach taken in switchable topologies. Changing the operation mode according to the line voltage can lead to an effective reduction of the line range, resulting in reduced component stress. Switchable topologies are already a well known approach but one of the original contributions of this paper is the construction of a switchable topology that switches between the same basic topology, in this case a boost type. The boost topology is in particular a good choice for ac/dc converters. This new type of switchable converter has been made possible by using a new approach called "The series voltage-source"-approach.

As long as the step-up ratio of the boost converter is kept below approximate a factor of 2 the conversion efficiency is typically above or in the area of $95 \%$. The drastic drop in the efficiency occurs as the step-up ratio increases. The larger the step-up ratio the larger the losses in the boost switch (conduction and switching). In order to avoid this scenario, the main objective of this research has been to find a way of keeping the boost converter operating in a more ideal setup. The basic idea is shown in Fig. 1.

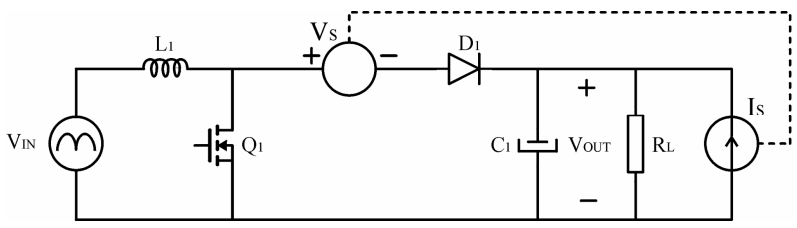

Fig. 1. Boost converter with a voltage source in series with the output. 


\section{A. Voltage-source Requirements}

The operation of the scheme shown in Fig. 1 can be divided into two normal operation modes, $\mathrm{V}_{\mathrm{AC}}<\mathrm{V}_{\mathrm{OUT}}$ and $\mathrm{V}_{\mathrm{AC}}>$ $\mathrm{V}_{\text {OUT. }}$.

The operation mode related to $\mathrm{V}_{\mathrm{IN}}<\mathrm{V}_{\text {OUT }}$ is shown in Fig. $2 a$. In this mode the voltage-source is an effective shortcircuit and the standard boost converter is easy to recognize. Fig. $2 b$ shows the resulting circuit when $V_{\text {IN }}>V_{\text {OUT. }}$. The switch $\mathrm{Q}_{1}$ is now inactive so the control of the converter is governed by the voltage-source which switches between 0 and a predetermined voltage, $\mathrm{V}$. The duration of which the voltage-source is zero, is duty-cycle controlled.

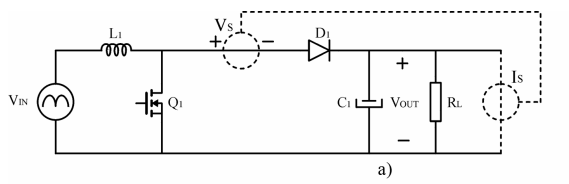

$\mathrm{V}_{\mathrm{s}}=0, \mathrm{Is}=0$
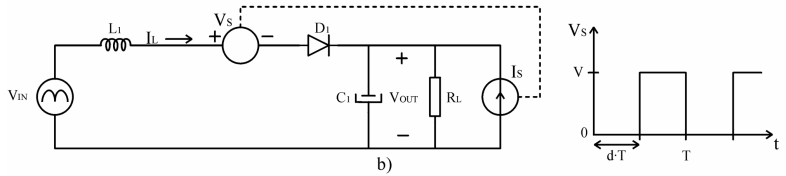

Fig. 2. Normal operation modes for the boost-boost switchable topology. a) $\mathrm{V}_{\mathrm{IN}}<\mathrm{V}_{\text {OUT }}, \mathrm{V}_{\mathrm{S}}=0, \mathrm{I}_{\mathrm{S}}=0$. b) $\mathrm{V}_{\mathrm{IN}}>\mathrm{V}_{\text {OUT }}$, the $\mathrm{V}_{\mathrm{S}}$-voltage alternates between 0 and $\mathrm{V}$.

For the above scheme to work a basic requirement apply to the voltage- and current-source arrangement. The power obtained by the voltage-source must be delivered by the current-source to the output.

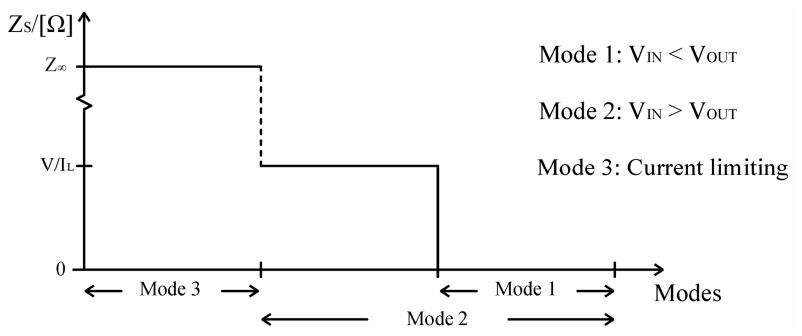

Fig. 3. Impedance of the voltage source and the related operation modes

If the switchable boost-boost converter of Fig. 1 should be able to control the inrush current, the voltage-source must be able to exhibit the characteristics of infinite impedance. The voltage-source impedance should therefore be able to be controlled according to Fig. 3.

In case of a current limiting situation (inrush or fault related), the voltage-source should be able to assume a high impedance, so that the current path to the output is disrupted (or almost). This is shown in Fig. 3 as the third mode (current limiting mode). The related source impedance increases to an infinite value theoretically. In the second mode the source impedance switches between zero (ideally) and the source voltage divided by the inductor current. In the first mode the voltage-source should be a short circuit so the related source impedance is ideally zero.

\section{B. Current-source Requirements}

Since the direction of the power flow is from the voltagesource to the current-source, the current-source should not constitute any load to the output terminals. Like an ideal current-source, the input impedance should be as high as possible. The other basic requirement is that the currentsource is able to transfer the energy obtained by the voltagesource, to the output.

\section{Basic Implementations of the Voltage-source}

Because of the requirements that the voltage-source has to meet, the obvious choice would be to implement the voltage-source as a regulated switch-mode power supply (SMPS). The SMPS is represented as a two-port network, where the first port functions as a voltage-source and the second port as a current-source. The power transfer is assumed to be unidirectional and the direction of the energy flow is from port \#1 (voltage-source) to port \#2 (currentsource).

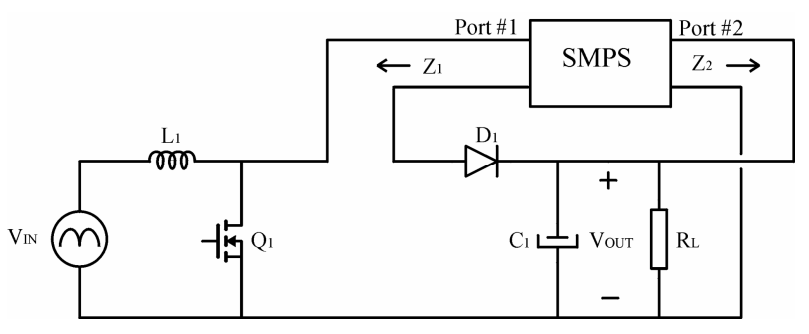

Fig. 4. SMPS implementation of the voltage source.

By looking at the realization in Fig. 4, it is clear to sea that not all types of SMPS are suited for the voltage-source implementation. Since the two input ports are referenced to different nodes in the circuit, only a specific group of converters, which consists of isolated converters and buckboost derived converters, can be used.

The input ports to the SMPS block have been characterized as a voltage-source (port \#1) and a current-source (port \#2) fulfilling the previous defined specifications. If we turn to the impedance that the two ports, \#1 and \#2, are loaded with (defined as Z1 and Z2), we discover that port \#1 is looking into a current-source (high impedance) formed by the inductor, and that port \#2 is looking into a voltage-source comprised of the output capacitor. This duality is not a coincidence and for all practical circuits this will always be the case, since it makes no sense to have series connected current-sources and parallel connected voltage-sources.
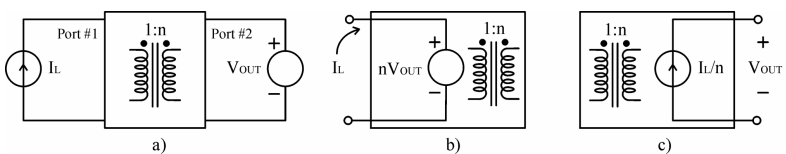

Fig. 5. a) Transformer coupled voltage/current source implementation. b) Reflected output voltage seen from port \#1. c) Reflected input inductor current seen from port \#2. 
The duality can be exploited by coupling port \#1 and port \#2 through a transformer. The voltage-source characteristics needed for port $\# 1$, are provided by the reflected output voltage as shown in Fig. 5b. In the same manner, the current-source characteristics of port \#2, are provided by the reflected input inductor. The energy transfer from port \#1 to port \#2 is also accomplished by the transformer implementation.

\section{TRANSFORMER-BASED EWiRaC CONVERTERS}

The transformer-based solutions do not need any energy storage elements, only means to control the transformer in such a way that the voltage-source requirements can be met. Following the ideas and considerations of the previous section, a new family of switchable boost-boost converters can be constructed.

\section{A. Standard Transformer-based EWiRaC Converters}

In the solution shown in Fig 6, the combination of the input inductor L1 and transformer arrangement forms an isolated boost converter where the primary-side-section is in series with the output voltage. The primary-side transformer configuration can be recognized as a push-pull configuration and the secondary-side rectification is a full-bridge configuration.

Before other configurations of the EWiRaC are presented, a brief introduction to the operation of the circuit shown in Fig. 6 will be given.

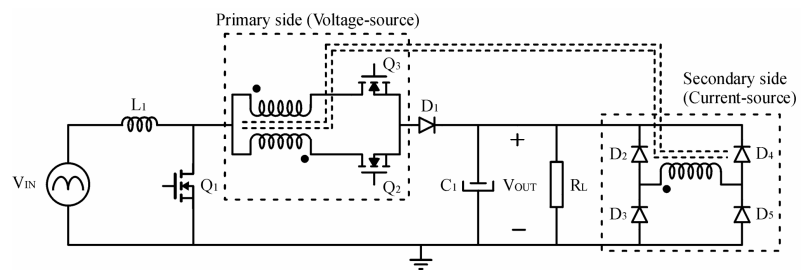

Fig. 6. EWiRaC. Push-pull primary-side, full-bridge secondary-side rectifier.

In the range where the input voltage is below the output voltage, the EWiRaC is in standard boost mode, meaning that the voltage-source complex is shorted. This is accomplished by turning on both switches, $\mathrm{Q}_{2}$ and $\mathrm{Q}_{3}$, so that the flux in the primary-side winding will cancel.

When the input voltage rises above the output voltage, the normal boost switch $\mathrm{Q}_{1}$ will be turned off for the duration of this period. In this mode the charging of the inductor is accomplished by turning on both switches $\mathrm{Q}_{2}$ and $\mathrm{Q}_{3}$. Since $\mathrm{V}_{\text {IN }}$ is greater than $\mathrm{V}_{\text {OUT }}$ this will result in a positive di/dt of the inductor current. At some point either $\mathrm{Q}_{2}$ or $\mathrm{Q}_{3}$ (alternating) will turn off and the inductor current will flow in the transformer winding where one of the switches is on. Since the flux is no longer cancelled the reflected output voltage will occur across the primary-side windings and result in a negative di/dt of the inductor current. An in-depth description of the circuit operation will be in the next section. Other well known primary- and secondary-side configurations exist that can be used in the EWiRaC. The more useful configurations are shown Fig. 7.

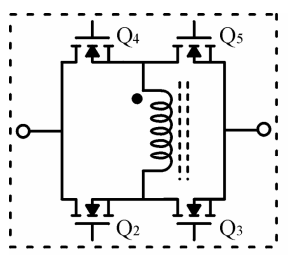

a) b)

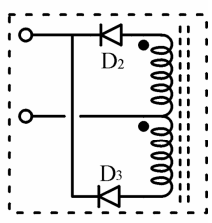

Fig. 7. Alternative voltage/current source implementations. a) Primary-side full-bridge switch. b) Secondary-side tapped-winding rectifier.

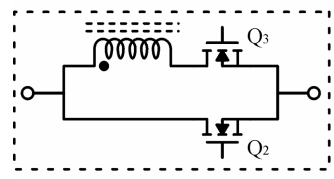

a)

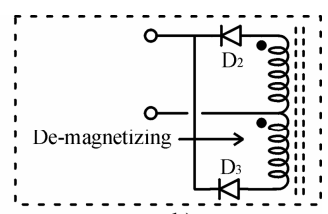

b)
Fig. 8. Single-ended version of the voltage/current source arrangement. a) Primary side. b) Secondary side.

With the alternative voltage and current source implementations shown in Fig. 7 we can construct 4 different EWiRaC converters. Single-ended versions could also be implemented but these configurations have limited operation ranges (duty-cycle constrains) or add excessive voltage stresses to the semiconductors. For the completeness on this section a single-ended version of the voltage/currentsource implementation is shown in Fig. 8.

\section{B. Alternative Transformer-based EWiRaC Converters}

Interleaved boost converters are well known and this concept can also be used with the EWiRaC. An interleaved version of the EWiRaC can be constructed by using the dual inductor push-pull isolated boost converter [5]. By using the duality between the boost and the buck converters, the dualinductor boost converter can be derived from the Hybridge converter [6] (also know as the current-doubler).

Besides the usual advantages achieved by interleaving, the dual-inductor EWiRaC offers further advantages. In the operation mode where the input voltage is below the output voltage, the voltage-source complex should in theory be a short circuit but for practical circuits resistance in the primary-side winding and the MOSFETs introduces some losses. For the dual-inductor EWiRaC the primary winding is bypassed in the low voltage mode. Further more, as for the Hybridge-configuration the dual-inductor EWiRaC can be integrated onto the same core. 


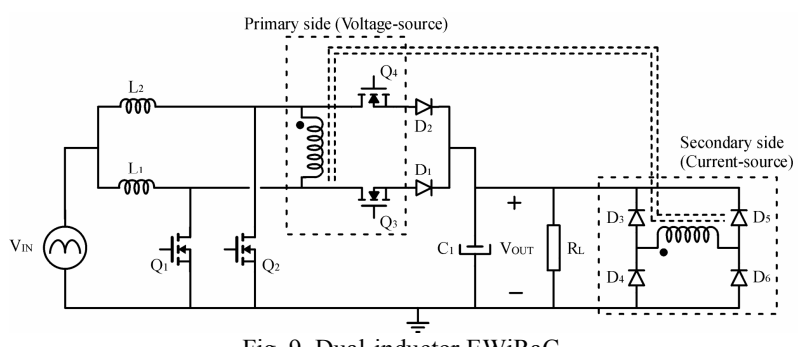

Fig. 9. Dual-indüctor EWiRaC.

The transformers in the EWiRaC converters are implemented in order to create an effective voltage source in series with the output. Non-isolated transformer types like the Autotransformer can also be used. Fig. 10 shows the Auto-transformer EWiRaC.

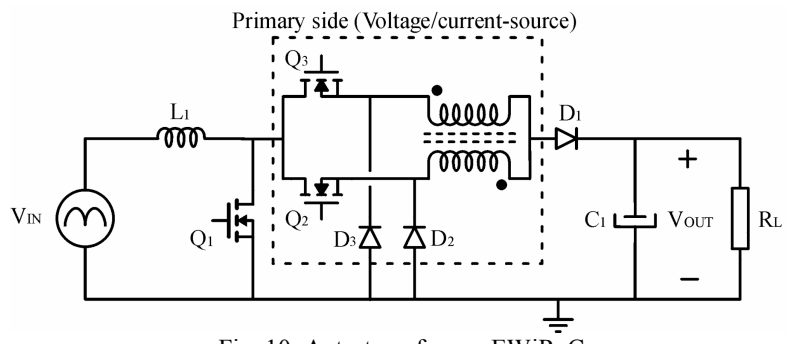

Fig. 10. Auto-transformer EWiRaC.

The structure of the EWiRaC becomes more simple in the auto-transformer configuration since the secondary side winding can be omitted. The auto-transformer usually offers a much better utilization compared to an isolation transformer. In a normal transformer design, the winding area would be split in two - one half to the primary-side windings and one half to the secondary-side windings. Since there are no secondary-side windings in the auto-transformer all the winding area can be utilized for the primary-side windings which makes this structure particular useful in the EWiRaC.

\section{EWiRaC OPERATION MODES}

The EWiRaC is only attractive if the desired output voltage is inside the line voltage range, otherwise the mode change will not come into effect and it has therefore little meaning to implement the EWiRaC if the output voltage should be higher than the maximum line voltage. In this analysis we assume, that the output voltage is below the maximum occurring line voltage. The implementation shown in Fig. 11 is the same as the one shown in Fig. 6.

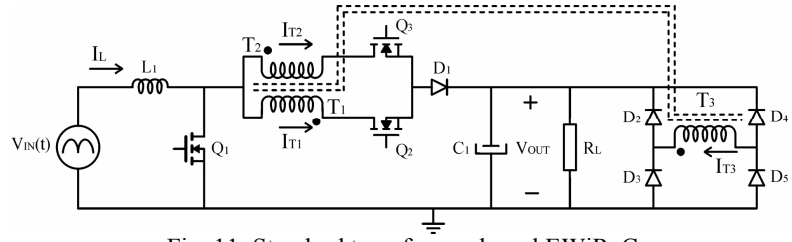

Fig. 11. Standard transformer-based EWiRaC.
The transformer configuration shown in Fig. 11 is a pushpull primary and a full-bridge secondary. The relations between the windings $T_{1}-T_{3}$ can be written as:

$T_{1}: T_{2}: T_{3}=1: 1: n$

For $\mathrm{V}_{\text {IN }}(\mathrm{t})<\mathrm{V}_{\text {OUT }}$ the voltage-source complex is shorted meaning that the circuit becomes that of a standard boost converter. In this mode the input to output steady state transfer function is given by:

$\frac{V_{\text {OUT }}}{V_{I N}}=\frac{1}{1-d_{1}}$

, where $d_{1}$ is the duty-cycle applied to the switch $Q_{1}$. The effective duty-cycle applied to the switches $\mathrm{Q}_{2}$ and $\mathrm{Q}_{3}$ in this mode is given by $\mathrm{d}_{2}=1$.

For $V_{\text {IN }}(t)>V_{\text {OUT }}$ the boost switch $Q_{1}$ is turned off under the duration of this interval $\left(\mathrm{d}_{1}=0\right)$. The voltage-source becomes active and performs the conversion. In this mode the steady-state transfer function is given by:

$\frac{V_{\text {OUT }}}{V_{I N}}=\frac{n}{n+1-d_{2}}$

, where $\mathrm{n}$ is the transformer turns-ratio as defined by Eq. (1) and $d_{2}$ is the effective duty-cycle applied to the switches $Q_{2}$ and $\mathrm{Q}_{3}$.

A.. $V_{I N}(t)<V_{\text {OUT }}$

The timing diagram for the voltages and currents of interest is shown in Fig 13 and the equivalent circuits of each of the two modes are shown below in Fig. 12.
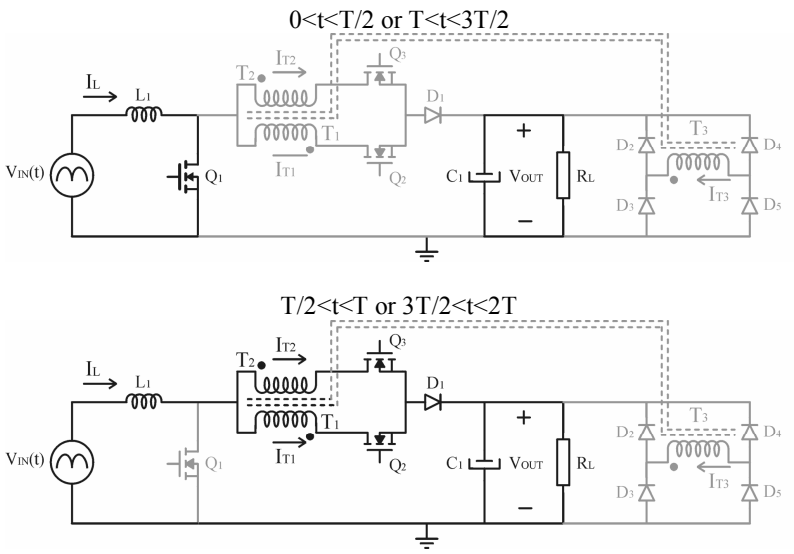

Fig. 12. Equivalent circuits for the two operation modes. 


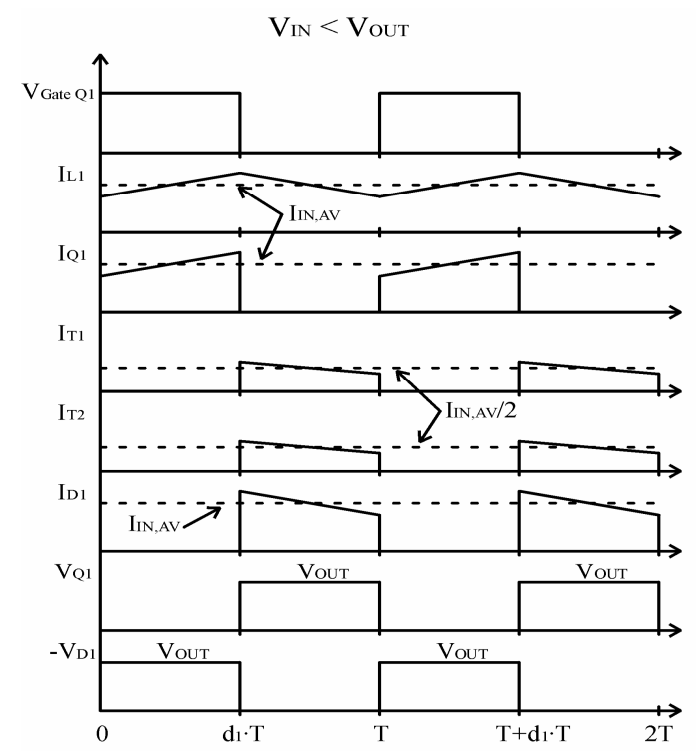

Fig. 13. Timing diagram of circuit voltages and currents $\left(\mathrm{V}_{\mathrm{IN}}<\mathrm{V}_{\text {OUT }}\right)$

In this mode the operation of the EWiRaC is exactly like the standard boost operation mode.

- $\quad$ At $t=0$, a gate signal is applied to Q1 turning it on. In this interval, the boost inductor is in the charge mode and the load is supplied entirely by the output storage capacitor.

- At the time d1·T the switch Q1 is turned off and the inductor current commutates to the voltage-source arrangement in series with D1. Since both Q2 and Q3 is turned on, the transformer flux is shorted and the voltage across each winding is ideally zero. Since the flux is cancelled, the transformer secondary (T3) is in-active. Assuming equal impedance of the series connection of T2, Q2 and T2, Q3 the inductor current will share equally between the two branches.

- $\quad$ At $t=\mathrm{T}$ the Q1 turns on again and the operations are repeated.

The voltage stresses on the switch Q1 and the diode D1 are in the boost mode equal to the output voltage.

B.. $V_{I N}(t)>V_{\text {OUT }}$

The timing diagram for the voltages and currents of interest is shown in Fig 15 and the equivalent circuits of each of the 4 modes are shown in Fig. 14. For the duration of this interval, the switch $\mathrm{Q}_{1}$ is turned off and the converter is working in the voltage-source mode.

- The switch cycle starts at $\mathrm{t}=0$ and both switches, Q2 and Q3, turns on. The two windings T1 and T2 are now effectively in parallel and referring to the winding dot notation, the flux is cancelled in the two primary windings. The transformer windings together with the switches can now be regarded as a short-circuit if the resistance and stray inductance of this connection is disregarded. The inductor charges in this mode since VIN >VOUT and the inductor current flows in both transformer windings $\mathrm{T} 1$ and T2. Since the transformer flux is cancelled, the secondary winding, $\mathrm{T} 3$, is inactive which also causes the diodes D2-D5 to be reversed biased.

- $\quad$ At $\mathrm{t}=\mathrm{d} 2 \cdot \mathrm{T}$ the switch Q3 turns off and the inductor current commutates to the $\mathrm{T} 1$ winding. The transformer flux is no longer shorted and the voltage across the windings $\mathrm{T} 1$ and $\mathrm{T} 2$ is clamped to the reflected output voltage according to the winding dot notation. The current in the primary winding $\mathrm{T} 1$ is transformed to the secondary winding $\mathrm{T} 3$ where the transformed current flows through D3 and D4.

- $\quad$ At $\mathrm{t}=\mathrm{T}$ a new inductor charge period starts by turning on the switch Q3. Again, the transformer flux is cancelled and the inductor current starts increasing.

- $\quad$ At $t=T+d 2 \cdot T$ the switch Q2 turns off and all of the inductor current commutates to winding $\mathrm{T} 2$. The primary current is transformed to the secondary winding T3 where the current is flowing through D2 and D5. The voltage on the secondary is clamped to the output voltage which couples to the primary windings according to the winding dot notation and the transformer turns-ratio.

- At $\mathrm{t}=2 \cdot \mathrm{T}$ a new switch-cycle starts and the 4 intervals is repeated.
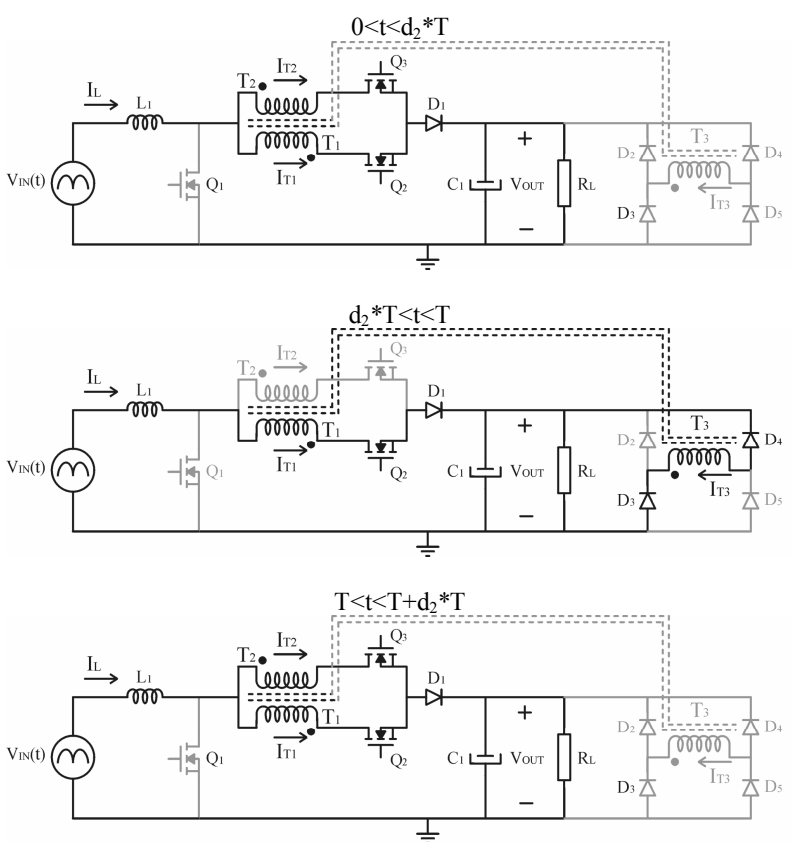


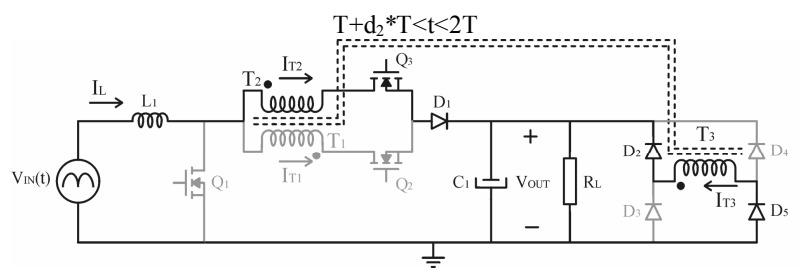

Fig. 14. Equivalent circuits for the 4 operation modes.

Compared to the standard boost mode $\left(\mathrm{V}_{\mathrm{IN}}<\mathrm{V}_{\text {OUT }}\right)$, the voltage-source mode uses two switching periods before repeating. The switches $\mathrm{Q}_{2}$ and $\mathrm{Q}_{3}$ are therefore operating at half the frequency of $Q_{1}$ but the effective inductor frequency is unchanged.

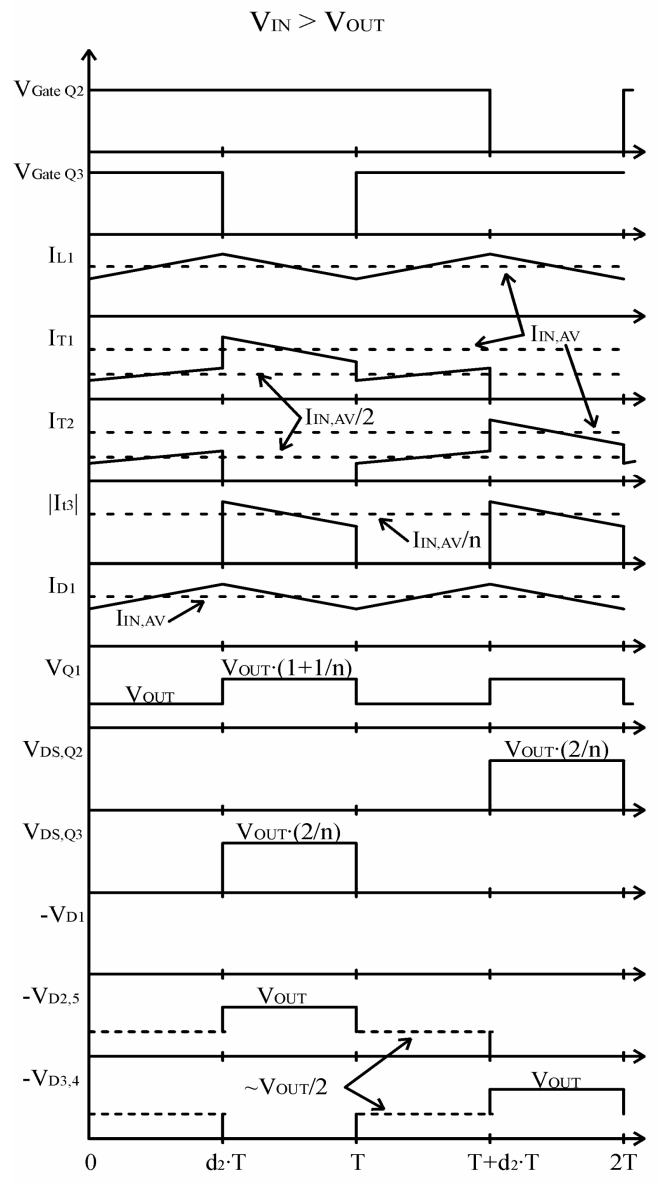

Fig. 15. Timing diagram of circuit voltages and currents $\left(\mathrm{V}_{\mathbb{N}}>\mathrm{V}_{\text {OUT }}\right)$

\section{COMPARISONS}

In this section the EWiRaC will be compared to the 2-switch buck-boost show in Fig. 16 (controlled as a switch-able converter, boost/buck ), and a standard boost converter. The boost converter is not capable of producing an output voltage below the line peak voltage so in reviewing these comparisons one should keep this in mind.

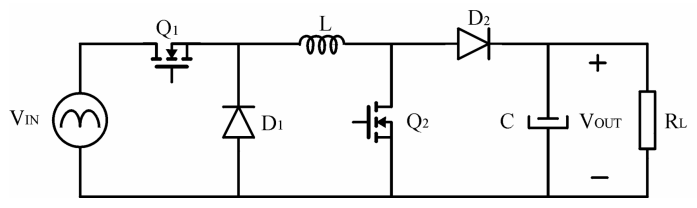

Fig. 16. Two-switch buck-boost converter.

\section{A. Active switches}

Table 1 summarizes the squared rms-currents relative to the output power and the estimated conduction losses using same die area per MOSFET. The input AC range is 3:1 and the output voltage for the 2-switch buck-boost and the EWiRaC is $200 \mathrm{~V}$ and $400 \mathrm{~V}$ for the boost converter.

\begin{tabular}{|l|c|c|c|}
\multicolumn{5}{|c|}{ TABLE 1} \\
\hline Norm $\left(\left(\mathrm{I}_{\mathrm{RMS}} / \mathrm{P}\right)^{2}\right)$ & 2-Sw. buck-boost & EWiRaC & Boost \\
\hline $\mathrm{Q}_{1}$ & $0.898^{*}$ & 0.416 & 0.657 \\
\hline $\mathrm{Q}_{2}\left(+\mathrm{Q}_{3}\right)$ & 0.416 & $0.482^{*}$ & - \\
\hline $\mathrm{P}_{\text {Conduction losses }}$ & 1 & 0.657 & 0.657 \\
\hline
\end{tabular}

* No associated switching losses

\section{B. Diodes}

For both the 2-switch buck-boost and the EWiRaC, the freewheeling diodes in the boost mode are subjected to twice the average current compared to the diode in the boost converter simply because of the difference in output voltage. The losses in these diodes are relatively insignificant but the associated reverse recovery currents of these diodes contribute considerably to the switching losses in the MOSFET. In a typical PFC boost implementation, the diode is made up by two $300 \mathrm{~V}$ diodes in series like the STTH806TTI from ST. Reducing the voltage rating of the diodes minimizes the reverse recovery problem considerable. The active diodes in the 2-switch buck-boost and the EWiRaC, should only be rated to the output voltage of $200 \mathrm{~V}$ which means that only one $300 \mathrm{~V}$ diode is necessary. So, for the same reverse recovery problems the diode conduction losses related to the average current are equal for all three implementations. Considering the losses associated with the diode rms-currents, the PFC boost converter will actually have higher losses caused by the larger average-to-rms current ratio.

\section{Inductors}

The worst case conduction losses in the inductors occur at low line where all three topologies operate in the boost mode. It is also at low line that the maximum flux density occurs. Another important factor with regard to the inductor stress is the maximum ac-flux which is proportional to the average voltage applied to the inductor. The size of the acflux changes with the line voltage and the three topologies exhibit different characteristics. 

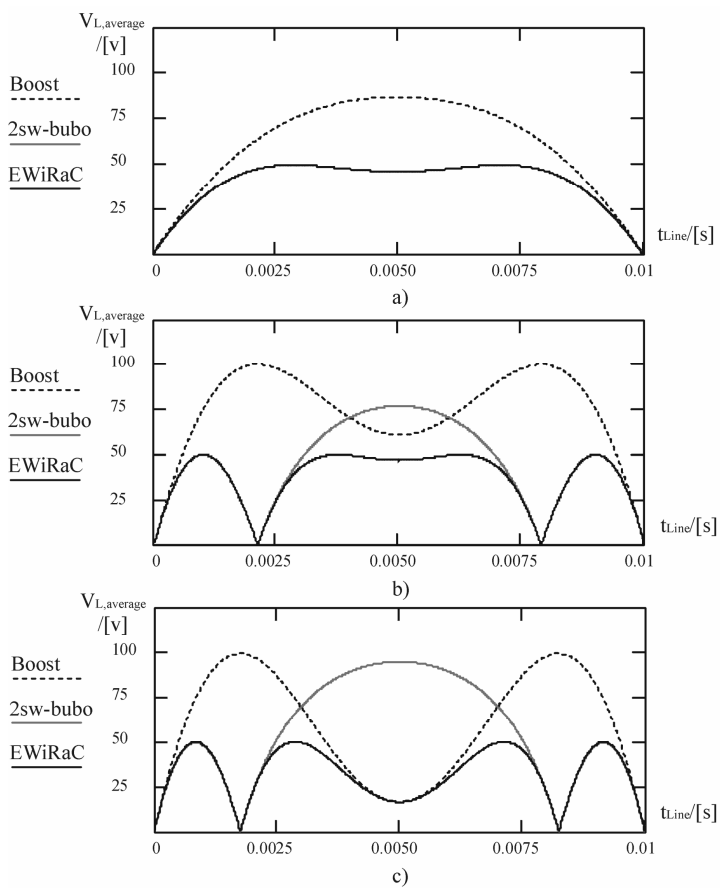

Fig. 17. Inductor comparison. a) $\mathrm{V}_{\mathrm{AC}}=90 \mathrm{~V}$. b) $\mathrm{V}_{\mathrm{AC}}=230 \mathrm{~V}$. c) $\mathrm{V}_{\mathrm{AC}}=270 \mathrm{~V}$.

In all of the above cases, the EWiRaC has better or equal performance compared to both the 2-Sw. buck-boost and the boost converter.

\section{EXPERIMENTAL RESULTS}

A prototype of the Auto-transformer based EWiRaC has been implemented as shown in Fig. 18.

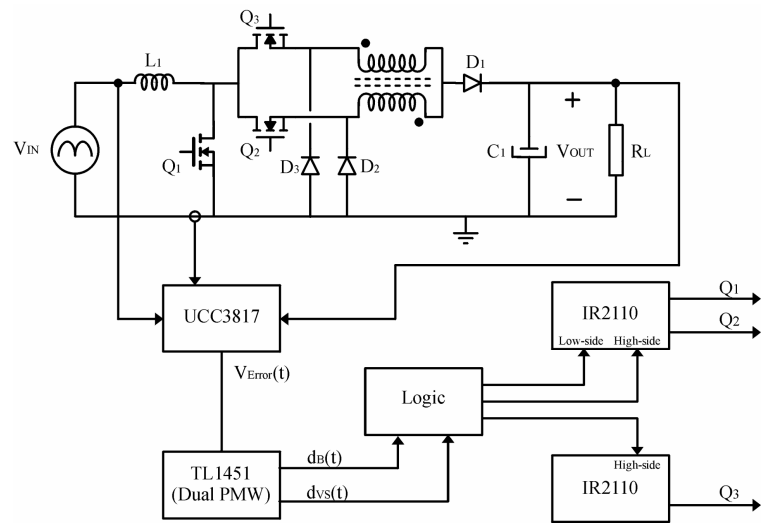

Fig. 18. Average current mode controlled Auto-transformer EWiRaC

[4] Lars Petersen, "High Efficient Rectifiers" PhD-Thesis. 2003. Technical university of Denmark

[5] De Aragao Filho, W.C.P.; Barbi, I.,"A comparison between two currentfed push-pull DC-DC converters-analysis, design and experimentation", INTELEC 1996, pp. 313-320.

[6] C. Peng, M. Hannigan, O. Seiersen, "A new efficient high frequency rectifier circuit", Proceedings of High Frequency Power Conversion 1991, pp. 236-243.

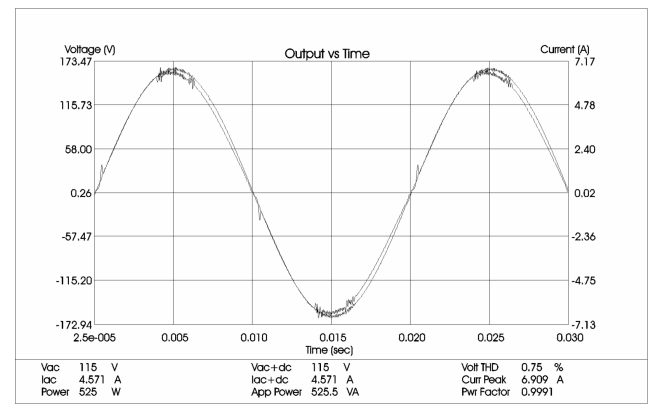

Fig. 19. Input voltage and currents at $\mathrm{V}_{\mathrm{AC}}=115 \mathrm{~V}$ and $\mathrm{P}_{\mathrm{OUT}}=500 \mathrm{~W}$

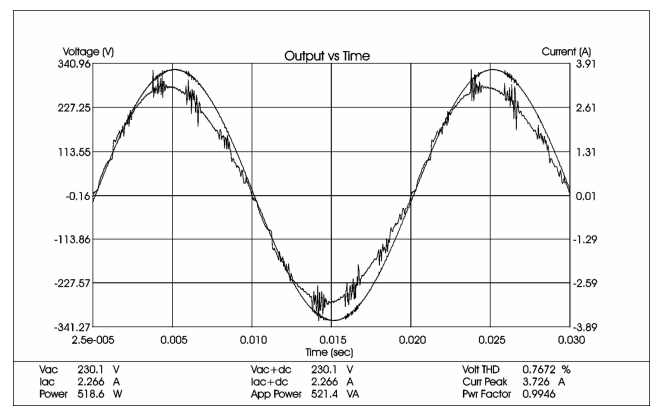

Fig. 20. Input voltage and currents at $\mathrm{V}_{\mathrm{AC}}=230 \mathrm{~V}$ and $\mathrm{P}_{\mathrm{OUT}}=500 \mathrm{~W}$

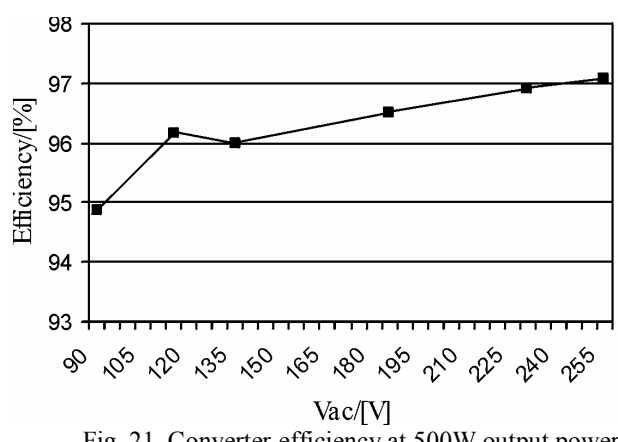

\section{CONCLUSION}

The real advantage of the $\mathrm{EWiRaC}$ shows at low-line where the efficiency is lifted by 1-2 percentage points. The thermal design is thereby eased considerable and smaller converter size and/or increased reliability is enabled.

\section{LEGAL NOTICE: Patent Pending}

\section{REFERENCES}

[1] Unitrode Power supply desing seminar SEM1000, Topic 1: J. Noon "A $250 \mathrm{kHz}, 500 \mathrm{~W}$ power factor correction circuit employing zero voltage switching"

[2] J.Chen, D. Maksomovic, R. Erickson "A new low-stress buck-boost converter for universal input PFC applications", APEC2001 pp.343-349

[3] L. Petersen, R. Erickson,"Reduction of voltage stresses in buck-boosttype power factor correctors operated in boundary mode", APEC2003, pp.664-670. 